\title{
Morfologia e agressividade de isolados de Phytophthora palmivora de cacaueiro no estado da Bahia
}

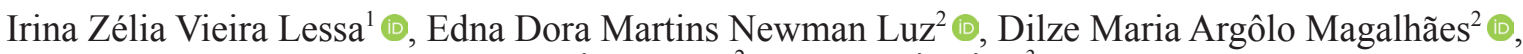

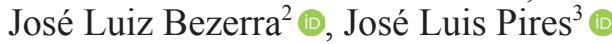

\begin{abstract}
${ }^{1}$ Programa de Pós-Graduação em Produção Vegetal, DCAA, Universidade Estadual de Santa Cruz - UESC, CEP- 45662-000, Ilhéus, BA, Brasil; ${ }^{2}$ Centro de Pesquisas do Cacau, Comissão Executiva do Plano da Lavoura Cacaueira, Ministério da Agricultura e Pecuária, Seção de Fitopatologia, CEP- 45600-970, Ilhéus, BA, Brasil. ${ }^{3}$ Centro de Pesquisas do Cacau, Comissão Executiva do Plano da Lavoura Cacaueira, Ministério da Agricultura e Pecuária, Seção de Genética, CEP- 45600-970, Ilhéus, BA, Brasil.
\end{abstract}

Autor para correspondência: Irina Zélia Vieira Lessa (irinalessa@hotmail.com)

Data de chegada: 09/04/2019. Aceito para publicação em: 19/12/2019.

$10.1590 / 0100-5405 / 222473$

\section{RESUMO}

Lessa, I.Z.V.; Luz, E.D.M.N.; Magalhães, D.M.A.; Bezerra, J.L.; Pires, J.L. Morfologia e agressividade de isolados de Phytophthora palmivora de cacaueiro no estado da Bahia. Summa Phytopathologica, v.46, n.3, p.228-235, 2020.

Diferentes espécies de Phytophthora são responsáveis por causar uma das doenças mais importantes do cacaueiro, a podridão parda, sendo P. palmivora a espécie predominante e bem distribuída mundialmente. Avaliou-se a morfologia e a agressividade de 100 isolados de P. palmivora, coletados em fazendas de 13 municípios da região cacaueira da Bahia, durante três anos consecutivos. Foram inoculados discos de folhas dos clones Scavina6 (SCA-6), padrão de resistência e SiC-23, padrão de suscetibilidade, com suspensões de cada um dos isolados, provenientes da coleção de Phytophthora Arnaldo Gomes Medeiros do Centro de Pesquisas do Cacau/CEPLAC, à concentração de $3 \times 10^{5}$ zoósporos/ mL. Foi utilizado o método patométrico escala de notas para avaliação da infecção sete dias após a inoculação. Avaliou- se o aspecto das colônias, a produção de esporângios e clamidósporos de cada isolado e foram mensuradas as estruturas de 61 isolados e a determinação do tipo de compatibilidade dos 100 isolados. Observou-se ampla variação na reação dos dois clones de cacaueiro aos isolados de P. palmivora, demonstrando diferentes graus de agressividade entre os mesmos. Esta agressividade não está relacionada ao local ou ano de coleta, pois isolados mais e menos agressivos foram obtidos nos mesmos municípios e anos de coleta. Houve também variação na morfologia das colônias. Os esporângios elipsóides a ovóides apresentaram dimensões médias de 28,3-50,5 x 18 -36,7 $\mu \mathrm{m}$, com pedicelos curtos $(1,5-4,4 \mu \mathrm{m})$ e relação comprimento largura variando de 1,1 a 2,2. Os clamidósporos, globosos terminais ou intercalares variaram de $18,4-43,5 \mu \mathrm{m}$ de diâmetro. Todos os 100 isolados são do tipo compatível A2. A variabilidade observada na agressividade dos isolados terá implicações nos estudos epidemiológicos e na seleção de genótipos resistentes a P. palmivora.

Keywords: Podridão parda. Theobroma cacao. Variabilidade. Caracterização morfométrica. Patogenicidade.

\section{ABSTRACT}

Lessa, I.Z.V.; Luz, E.D.M.N.; Magalhães, D.M.A.; Bezerra, J.L.; Pires, J.L.Morphology and aggressiveness of isolates of Phytophthora palmivora from cacao trees in Bahia state. Summa Phytopathologica, v.46, n.3, p.228-235, 2020.

Different Phytophthora species are responsible for causing one of the most important diseases of cacao, the black pod rot, and P. palmivora, well distributed worldwide, is the predominant species. Morphology and aggressiveness of 100 isolates of P. palmivora, collected from farms in 13 municipalities of the cacao growing region in Bahia State, were evaluated for three consecutive years. Leaf discs from the clones Scavina 6 (SCA-6), resistance standard, and SIC-23, susceptibility standard, were inoculated with suspensions of each of the isolates obtained from the Phytophthora Collection "Arnaldo Gomes Medeiros" of Cacao Research Center/CEPLAC, at the concentration of $3.0 \times 10^{5}$ zoospores $/ \mathrm{mL}$. A pathophysiological scale was used to evaluate the infection seven days after inoculation. Colony appearance and sporangium and chlamydospore production of each isolate were evaluated; the structures of 61 isolates were measured, and the type of compatibility of the 100 isolates was determined. Reaction of the two cacao clones to the isolates of P. palmivora had a great variation, demonstrating different degrees of aggressiveness among isolates. Such aggressiveness is not related to the site or the year of collection, since more and less aggressive isolates were obtained in the same municipalities and years of collection. There was also a variation in the morphology of colonies. Ellipsoid to ovoid sporangia had a mean size of $28.3-50.5 \times 18-36.7 \mu \mathrm{m}$, short pedicels $(1.5-4.4 \mu \mathrm{m})$ and length-width ratio ranging from 1.1 to 2.2 . Globose, terminal or intercalary chlamydospores ranged from 18.4 - $43.5 \mu \mathrm{m}$ in diameter. All 100 isolates were A2 compatible. The observed variability in the aggressiveness of $P$. palmivora isolates will have implications for the epidemiological studies and the selection of genotypes resistant to P. palmivora.

Palavras-chave: Black pod rot. Theobroma cacao. Variability. Morphometric characterization. Pathogenicity.

O cacaueiro (Theobroma cacao L.) é uma espécie dicotiledônea, nativa das florestas tropicais úmidas do continente Americano, pertencente à família Malvaceae, cujo centro de origem é a Amazônia. A planta é perene, arbórea, monóica, cauliflora, com inflorescências formadas em locais no tronco, denominados almofadas florais, compostas de flores hermafroditas e pentâmeras, que apresentam de 30 a 70 óvulos (8). Seu fruto, o cacau, é um produto nobre, cuja semente é matéria prima do chocolate, consumido mundialmente. É uma planta de grande valor econômico em mais de 50 países (36).

O Brasil já foi o segundo maior produtor de cacau do mundo, com uma produção de 350 mil toneladas, no fím da década de 70 , sendo a Bahia o principal estado produtor. Após o surgimento da 
Vassoura de Bruxa (VB) em 1989, no sul da Bahia, causada pelo fungo Moniliophthora perniciosa (Stahel) Aime \& Philips-Mora (= Crinipellis perniciosa (Stahel) Singer) ocorreu uma queda drástica da produção da Bahia (29). Assim, em 1997/98 houve uma reversão no quadro da balança comercial: o Brasil passou de exportador, a importador de cacau.

Através de pesquisas e programas de incentivos, deu-se início a recuperação da lavoura cacaueira, com o replantio e clonagem de materiais genéticos resistentes no campo. Com a diminuição da Vassoura de Bruxa ressurgiu outra doença de grande importância econômica, que tem afetado a produção de cacau desde os anos 20 do século passado, a Podridão Parda, causada por um complexo de espécies de Phytophthora de Bary (27). No Brasil, ocorrem P. palmivora (E. J. Butl.) E. J. Butler, P. citrophthora (R. E. S. m \& E. H. S. m.) Leonian, $P$. capsici Leonian e $P$. heveae A. J. Thomps. Entre essas espécies, $P$. citrophthora e $P$. palmivora são as mais agressivas nas plantações de cacau da Bahia (16). Foram testados 82 genótipos de cacaueiro na Bahia, e destes, apenas os clones PA-30 e PA-150 apresentaram resistência a $P$. palmivora, $P$. capsici e $P$. citrophthora, ao mesmo tempo, enquanto outros 19 materiais foram resistentes ora a uma ou duas espécies, mas nunca as três $(17,18)$.

A Podridão Parda é considerada a principal doença do cacaueiro em nível mundial, pois ocorre em todos os países produtores (23), causando perdas de 30 a $90 \%$ da produção dos frutos (3). No Estado da Bahia, essas espécies provocam redução na produção de cacau de até $80 \%$, pois atacam os frutos, além de outras partes vegetativas da planta (18).

Várias populações têm sido caracterizadas para resistência a Phytophthora, com avaliações feitas no campo (6) e inoculações artificiais de frutos e discos de folhas $(1,26,36)$. No Brasil, o uso de discos de folhas por ser um método precoce, não destrutivo, que pode ser repetido na mesma planta, tem sido uma boa opção para testar genótipos de cacaueiro, uma vez que folhas jovens podem ser atacadas naturalmente por Phytophthora, especialmente por P. palmivora, já que a estrutura histológica da face abaxial da folha é semelhante à camada superficial dos frutos (40). Uma escala de notas é usada na avaliação $(13,26)$ possibilitando comparar a reação dos genótipos de cacaueiro à Podridão Parda após inoculação pelo método de discos de folhas.

Embora seja conhecida a agressividade da espécie $P$. palmivora ao cacaueiro, nenhum estudo populacional foi realizado com isolados dessa espécie obtidos na região cacaueira da Bahia. Levando-se em consideração a necessidade de conhecer a variabilidade existente entre isolados deste patógeno, para uso no programa de melhoramento genético do cacaueiro à Podridão Parda, objetivou-se avaliar a agressividade de 100 isolados de P. palmivora, coletados em fazendas de 13 municípios produtores de cacau da Bahia, durante o período de três anos (2010-2012), a discos de folhas de cacaueiro dos clones Scavina 6 (SCA-6), padrão de resistência, e SIC-23, padrão de suscetibilidade e fazer a caracterização morfológica e determinação da compatibilidade sexual dos mesmos, visando observar diferenças que possam existir entre eles.

\section{MATERIAL E MÉTODOS}

As atividades foram realizadas na Seção de Fitopatologia do Centro de Pesquisa do Cacau/Comissão Executiva do Plano da Lavoura Cacaueira (SEFIT/CEPEC/CEPLAC). Foram utilizados 100 isolados de Phytophthora palmivora, coletados em 13 municípios produtores de cacau da Bahia, entre os anos de 2010, 2011 e 2012 (24) (Figura 1), que estavam preservados na coleção de Phytophthora Arnaldo Gomes Medeiros, do Laboratório de Phytophthora do CEPEC (CEPLAC, Ilhéus-Ba). Os números dos isolados são aqueles de registro dos mesmos na coleção, que é patrimônio genético do país. Todos os isolados foram removidos da coleção onde estavam preservados em óleo mineral ou água destilada esterilizada (Método de Castellani) e cultivados primeiro em meio seletivo PARPH (14) e posteriormente em meio cenoura-ágar (CA) a $25^{\circ} \mathbf{C}$ sob luz contínua por sete dias, para a caracterização morfológica do patógeno.

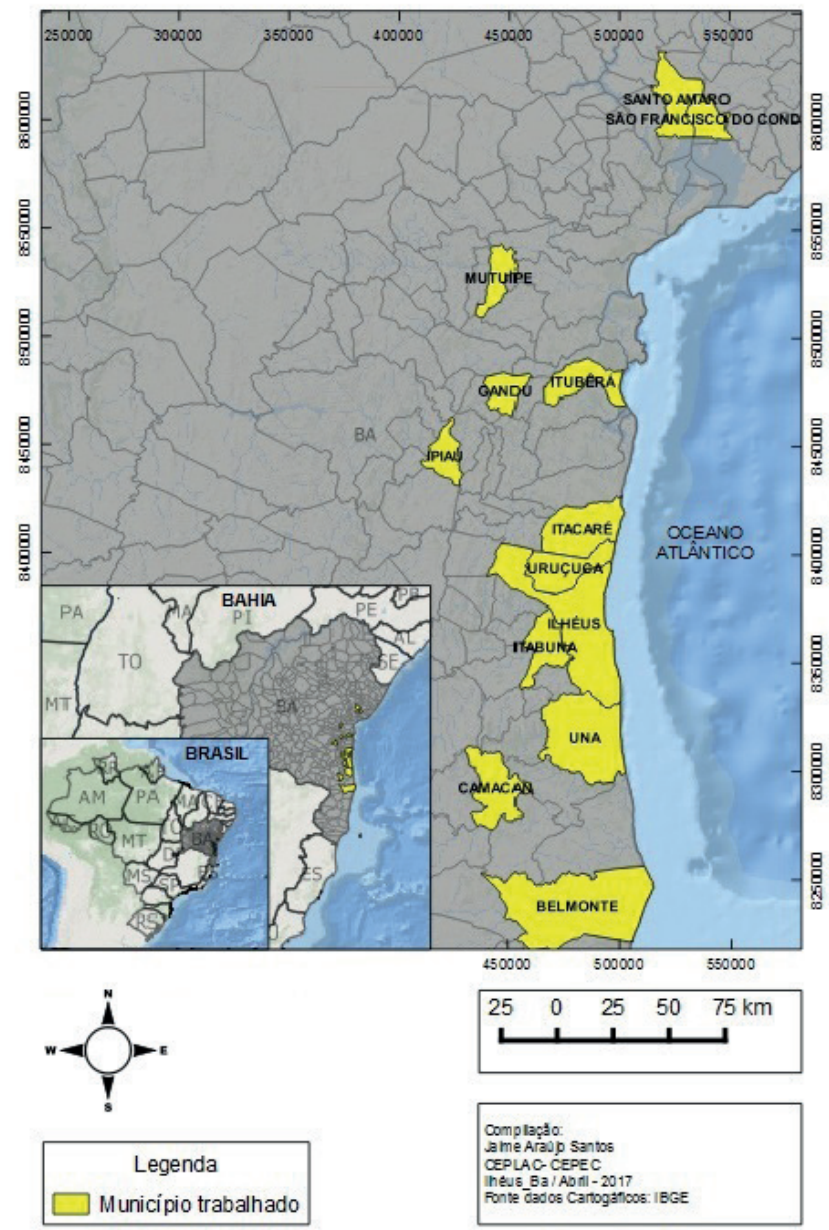

Figura 1. Mapa de distruição dos 13 municípios de coleta dos 100 isolados de Phytophthora palmivora estudados.

Inicialmente os isolados foram repicados para placas de Petri contendo meio de cultura CA (22), as quais foram mantidas sob iluminação constante à temperatura de $25^{\circ} \mathrm{C}(20)$. Após cinco dias de incubação, fragmentos das bordas das colônias com micélio foram transferidos para placas de Petri contendo meio seletivo PARPH, que foram mantidas no escuro. Após o crescimento em meio seletivo, foi feita nova repicagem para 10 placas de Petri de cada isolado contendo meio $\mathrm{CA}$ e as placas mantidas sob iluminação constante à temperatura de $25^{\circ} \mathrm{C}$ durante sete dias à temperatura de $25^{\circ} \mathrm{C}$, para a produção do inóculo (20). Em seguida, foram colocados $10 \mathrm{~mL}$ de água estéril gelada em cada placa, transferindo-as para geladeira onde permaneceram por 20 minutos. Após este período, as placas foram retiradas e colocadas à temperatura ambiente por mais 25 minutos a fim de acontecer a liberação dos zoósporos. Para proceder a contagem de zoósporos, $1 \mathrm{ml}$ 
da suspensão dos mesmos foi colocada sobre uma gota de FAA(Formol; Álcool; Ácido Acético Glacial) para imobiliza-los. A concentração da suspensão foi calculada em Câmara de Newbauer, e ajustada para 3,0 x $10^{5}$ zoósporos/ mL.

Foram coletadas, folhas em estádio intermediário de maturação, baseado na mudança de coloração do pecíolo de verde começando a ficar marrom, dos clones SCA-6 e SIC-23 de cacaueiro, considerados respectivamente, como resistente e suscetível à Podridão Parda (17), nas primeiras horas da manhã, para evitar a incidência do sol e manter as folhas túrgidas, que posteriormente, foram levadas para o Laboratório de Phytophthora (CEPEC/CEPLAC), onde foram desinfestadas superficialmente e cortados discos de $1,5 \mathrm{~cm}$ de diâmetro, com um cortador semiautomático. Os discos foram dispostos com a face abaxial para cima, em caixas plásticas forradas com espuma esterilizada úmida. O delineamento experimental adotado foi em blocos ao acaso, para maior confiabilidade e repetibilidade, contendo fileiras de 10 discos de folhas de cada um dos genótipos avaliados, correspondentes aos clones SCA-6 e SIC-23 numa mesma caixa, em quatro repetições (caixas), totalizando $40 \mathrm{discos} /$ isolado/ clone. Cada disco foliar em uma fileira de 10 recebeu $10 \mu \mathrm{L}$ de suspensão de inoculo na concentração $3,0 \mathrm{x}$ $10^{5}$ zoósporos $/ \mathrm{mL}$ obtida de cada um dos isolados estudados. Após a inoculação, as caixas com os discos foram fechadas, para manter umidade relativa em torno $100 \%$, e acondicionadas a $25^{\circ} \mathbf{C}$, por sete dias, ao abrigo de luz. Após este período, a avaliação foi feita usando o método patométrico em escala de notas (26), com valores variando de $0-5$ que correspondem ao seguinte: 0 - sem sintoma; 1 - pequenos pontos cloróticos; 2 - pontos cloróticos conectando-se entre si; 3 - pontos necróticos coalescentes; 4 - lesão marrom em expansão; 5 - lesão necrótica grande. A cada disco foi atribuída uma nota da escala e calculada a média dos 40 discos para cada genótipo. Os dados foram submetidos à análise de variância para comparação de médias pelo teste $\mathrm{F}$ ao nível de $1 \%$ de probabilidade e pelo teste de "Tukey Lines" a 5\% de probabilidade usando o sistema estatístico "Statistical Analysis Sistem" (31) através do procedimento "General Linear Models Procedure" (PROC GLM).

Após a avaliação da agressividade dos isolados aos discos de folhas dos clones SIC-23 e SCA-6, foram escolhidos para caracterizar morfologicamente 61 isolados $(1546,1547,1548,1669,1670,1678$, $1706,1733,1735,1743,1744,1762,1764,1767,1778,1779,1795$, $1818,1825,1845,1862,1878,1913,1985,1971,1900,2117,2118$, 2125, 2171, 2208, 2219, 2227, 2251, 2293, 2297, 2302, 2307, 2321, $2323,2345,2348,2351,2363,2364,2402,2433,2428,2460,2466$, 2469, 2489, 2496, 2498, 2500, 2502, 2505, 2508, 2530, 2531 e 2607), seguindo o critério de seleção entre aqueles considerados mais e menos agressivos. As colônias foram crescidas em placas de Petri contendo meio de cultura $\mathrm{CA}$, para serem observados entre cinco a 10 dias de idade, dependendo do período de esporulação de cada isolado, os seguintes caracteres de valor taxonômico: i) esporângios: presença ou ausência, comprimento, largura, razão comprimento/ largura, caducidade, comprimento do pedicelo, tipo de papila, abertura e profundidade do poro apical; ii) clamidósporos: presença ou ausência e diâmetro. As medidas foram efetuadas em 20 repetições de cada tipo de esporo para cada isolado, através de lâminas observadas ao microscópio ótico (modelo Primo Star, Zeiss). A caracterização das colônias foi feita observando-se as características macroscópicas, como a forma e tipo de crescimento (petalóide, estrelar, roseta, irregular, zonada, concêntrica) e o tipo de micélio aéreo (ralo, farináceo, cotonoso, floculoso) $(21,22,37,41)$.

Para determinar o grupo de compatibilidade dos 100 isolados de $P$. palmivora estudados, foi avaliada a formação dos oósporos por meio do pareamento destes isolados através do método de sanduíche (22), com os isolados padrões para os grupos de compatibilidade A1 (isolado 1191), obtido de plantas de mamoeiro e A2 (isolado 216) de cacaueiro, provenientes da Coleção de Phytophthora Arnaldo Gomes Medeiros. Todos os isolados foram cultivados em placas de Petri contendo meio CA, durante sete dias. Após esse tempo, discos de 5,0 mm de diâmetro contendo micélio dos isolados A1 e A2, foram pareados (sobrepostos) com discos de cada um dos 100 isolados e montados em placas de Petri pequenas de $6 \mathrm{~cm}$ de diâmetro. Em seguida, as placas foram mantidas no escuro por sete dias.

Para observação da formação de oósporos, retirou-se o disco central e com uma alça de ponta reta, raspou-se a sua superfície. O material fúngico raspado foi colocado em gota de lactofenol em lâmina de microscopia e observado ao microscópio ótico (modelo Primo Star, Zeiss). A compatibilidade foi constatada pela presença ou ausência de oósporos, indicando a qual grupo de compatibilidade os isolados pertencem.

\section{RESULTADOS E DISCUSSÃO}

Os dados submetidos à análise de variância foram altamente significativos $(\mathrm{p} \leq 0,001)$, tanto para os efeitos de clone, município, ano de coleta, isolado e das interações município $\mathrm{x}$ ano e isolado $\mathrm{x}$ município $x$ ano (Tabela 1). Os clones SCA-6 e SIC-23 apresentaram níveis médios de infecção de 1,53 e 2,24, respectivamente e reação diferenciada para todos os isolados de $P$. palmivora conforme já era esperado, uma vez que SCA-6 é considerado resistente e SIC-23 suscetível a Podridão Parda (17). Esta mesma relação foi comprovada ao estabelecerem uma escala de notas para comparação das reações de diferentes clones de cacaueiro às espécies de Phytophthora, através de inoculação de frutos (15).

Tabela 1. Análise de variância da agressividade de isolados de Phytophthora palmivora.

\begin{tabular}{lccccc}
\hline Fonte de variação & GL & SQ & QM & F (valor de p) \\
\hline Clones & 1 & 1016,02 & 1016,02 & 1502,55 & $(<0,001)$ \\
Municípios & 12 & 139,75 & 11,65 & 91,08 & 17,22 \\
Anos & 2 & 182,17 & 8,48 & 134,70 & $(<0,001)$ \\
Isolados & 70 & 593,49 & 16,41 & 24,28 & $(<0,001)$ \\
Municípios*Anos & 15 & 246,22 & & \\
\hline Total corrigido & 7999 & 7518,97 & & \\
\hline
\end{tabular}

Coeficiente de variação $(\mathrm{CV} \%)=43,63$ 
Dentre os isolados dos 13 municípios testados, comprovou-se que os provenientes de São Francisco do Conde, Una, Camacan e Ilhéus foram os mais agressivos aos dois clones, seguido dos de Mutuípe e Belmonte, que não diferiram do grupo anteriormente citado, mas também não diferiram do grupo formado pelos isolados de Uruçuca, Gandú, Itacaré e Itabuna, que podem ser considerados de agressividade moderada. Os isolados provenientes de cacaueiros cultivados em Ituberá e Santo Amaro não diferiram estatisticamente dos de Ipiaú, que foram considerados os menos agressivos (Tabela 2).

Tabela 2. Comparação de médias ${ }^{1}$ de infecção entre os treze municípios de coleta dos 100 isolados de Phytophthora palmivora testados.

\begin{tabular}{lcc}
\hline Municípios & Médias & \\
\hline São Francisco do Conde & 2,12 & $\mathbf{a}$ \\
Una & 2,09 & $\mathbf{a}$ \\
Camacan & 2,03 & $\mathbf{a}$ \\
Ilhéus & 2,02 & $\mathbf{a}$ \\
Mutuípe & 1,95 & $\mathbf{a b}$ \\
Belmonte & 1,95 & abc \\
Uruçuca & 1,83 & bcd \\
Itacaré & 1,82 & bcd \\
Itabuna & 1,81 & bcde \\
Gandú & 1,81 & bcde \\
Ituberá & 1,78 & cde \\
Santo Amaro & 1,72 & de \\
Ipiaú & 1,64 & e \\
\hline
\end{tabular}

${ }^{1}$ Teste de comparação de médias Tukey $(\alpha=0,05)$. As médias de tratamentos seguidas de pelo menos uma letra em comum na coluna não diferem entre si.

Quanto ao efeito de ano de coleta dos isolados (Tabela 3), observouse que as reações dos isolados variaram a cada ano, e que houve maior agressividade dos isolados obtidos em 2011 (nível médio de infecção 2,086) do que em 2010 (1,751) e em 2012 (1,663), sendo este último aquele em que os isolados mostraram-se menos agressivos em relação aos outros dois anos de coleta.

Tabela 3. Comparação de médias ${ }^{1}$ de infecção entre os anos de coleta dos 100 isolados de Phytophthora palmivora testados.

\begin{tabular}{cc}
\hline Ano de coleta & Médias \\
\hline 2011 & a 2,05 \\
2010 & b 1,81 \\
2012 & c 1,67 \\
\hline
\end{tabular}

${ }^{1}$ Teste de comparação de médias Tukey $(\alpha=0,05)$. As médias de tratamentos seguidas de pelo menos uma letra em comum na coluna não diferem entre si.

Para a interação município e ano de coleta (Tabela 4), embora entre os 100 testados, não tenha sido possível ter-se isolados de todos os municípios em todos os anos de coleta, observou-se também a variação na agressividade dos isolados por município, de ano para ano. Por exemplo, em 2011 os isolados mais agressivos foram os coletados em Belmonte, Ilhéus e São Francisco do Conde, enquanto entre os de menor agressividade, para os coletados naquele ano, estavam os de Camacan e Uruçuca, que, nos anos de 2011 e 2012 foram os municípios com isolados de maior agressividade. Quanto ao município de Itabuna não houve diferença estatística para as médias dos anos de 2010 e 2011 e ambos diferiram da média de 2012, embora tenham sido testados quatro isolados coletados em 2011 e apenas um para cada um dos outros anos. Apenas em Camacan, a média dos isolados de 2012 superou estatisticamente a de 2010.

Tabela 4. Comparação de médias ${ }^{1}$ de infecção entre os 100 isolados de Phytophthora palmivora testados divididos pelos treze municípios e anos de coleta (2010-2012).

\begin{tabular}{lccc}
\hline \multirow{2}{*}{ Municípios } & \multicolumn{3}{c}{ Médias/Anos } \\
\cline { 2 - 4 } & $\mathbf{2 0 1 0}$ & $\mathbf{2 0 1 1}$ & $\mathbf{2 0 1 2}$ \\
\hline Belmonte & $2,31 \mathbf{a}$ & $1,96 \mathbf{d e f}$ & $1,58 \mathbf{~ b}$ \\
Ilhéus & $2,26 \mathbf{a b}$ & $2,02 \mathbf{c d e}$ & $1,64 \mathbf{b}$ \\
São Francisco do Conde & $2,12 \mathbf{a b}$ & - & - \\
Una & $2,05 \mathbf{b}$ & $2,12 \mathbf{~ b c d}$ & - \\
Itabuna & $2,05 \mathbf{b}$ & $1,88 \mathbf{~ f f}$ & $1,29 \mathbf{c}$ \\
Mutuípe & $1,75 \mathbf{c}$ & $2,21 \mathbf{b c}$ & - \\
Santo Amaro & $1,70 \mathbf{c}$ & $1,75 \mathbf{c}$ & $1,66 \mathbf{b}$ \\
Ipiaú & $1,64 \mathbf{c}$ & - & - \\
Gandú & $1,62 \mathbf{c}$ & $1,96 \mathbf{d e f}$ & - \\
Ituberá & $1,62 \mathbf{c}$ & $2,03 \mathbf{c d e}$ & $1,61 \mathbf{b}$ \\
Camacan & $1,60 \mathbf{c}$ & $2,66 \mathbf{a}$ & $2,06 \mathbf{a}$ \\
Uruçuca & $1,57 \mathbf{c}$ & $2,28 \mathbf{b}$ & $1,66 \mathbf{b}$ \\
Itacaré & - & - & $1,82 \mathbf{a b}$ \\
\hline
\end{tabular}

${ }^{1}$ Teste de comparação de médias Tukey $(\alpha=0,05)$. As médias de tratamentos seguidas de pelo menos uma letra em comum na coluna não diferem entre si. (-) ausência de isolados para este município/ano. Não avaliado.

É importante notar que, o ano de 2011 apresentou os isolados com os níveis médios de maior agressividade (Tabela 3), em relação aos isolados coletados nos outros anos, bem como os isolados considerados de menor agressividade entre todos os isolados testados. Dados do CEPEC, coletados em diversos municípios sobre o percentual de frutos infectados pela Podridão Parda na Bahia, no período de janeiro de 2010 a novembro de 2012, como é possível observar no gráfico (Figura 2), corroboram com este resultado, pois o ano de 2011 obteve percentuais de frutos infectados mais elevados do que nos anos de 2010 e 2012, indicando que, possivelmente, a ocorrência da Podridão Parda no campo, está correlacionada à predominância de isolados mais agressivos na população naquele ano.

Os valores médios de infecção obtidos para os isolados testados neste experimento variaram de 2,95 (isolado 1744, coletado em Camacan no ano de 2011) a 1,14 (isolado 2531, coletado em Itacaré no ano de 2012), o que demonstra a ampla variação na agressividade dos isolados testados. $\mathrm{O}$ valor da diferença média significativa calculada pelo Teste de Tukey $(\mathrm{p}>0,01)$ foi $0,5597(\approx 0,56)$. Um grupo de isolados 


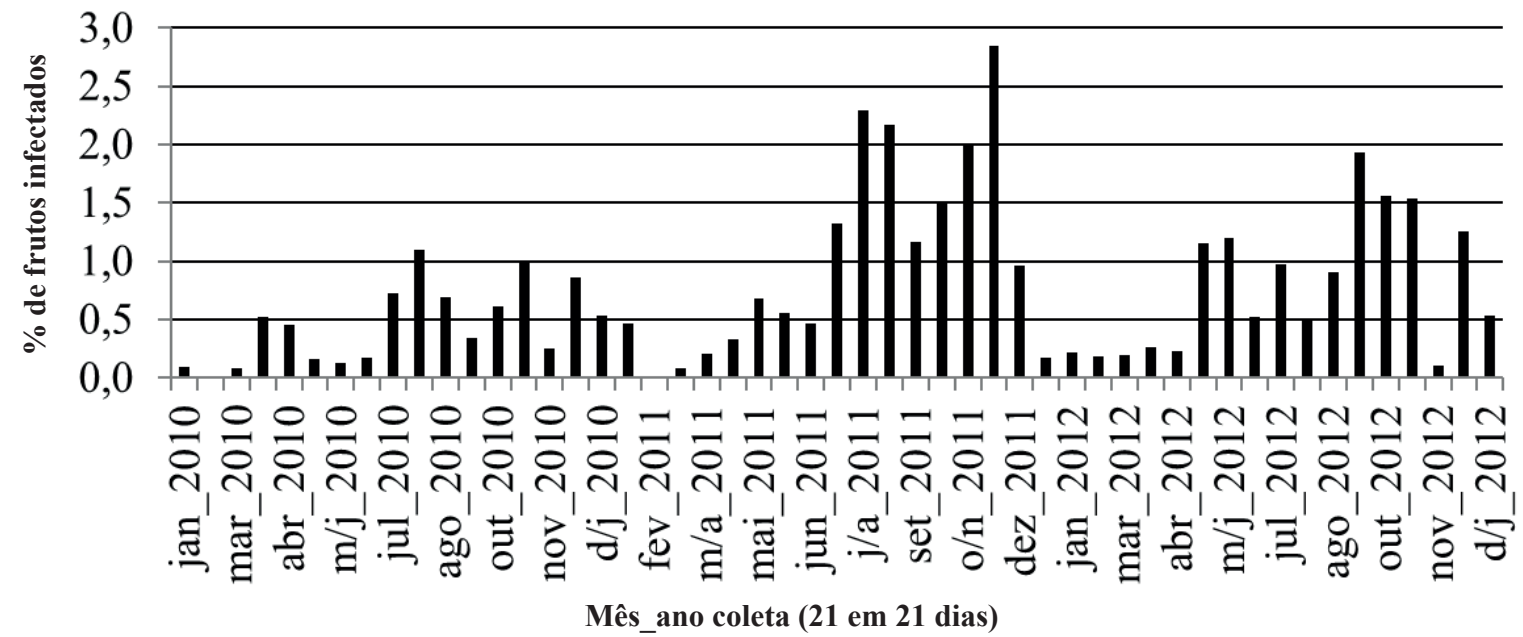

Figura 2. Dados percentuais (\%) de frutos de cacau infectados por Podridão Parda na Bahia, entre janeiro de 2010 a dezembro de 2012.

destacou-se como altamente agressivo aos clones testados e que não diferiram significativamente do isolado 1744. Foram eles 1778 e 1735 (de Camacan), 1845 (Mutuípe), 1913 (Belmonte), 1878 (Una), 1985 e 1971 (Ilhéus), 1733 (São Francisco do Conde) e 1767 (Belmonte). No entanto, os isolados que tiveram níveis médios de infecção superiores a 2,0 também foram considerados agressivos. Estes isolados são de procedências diversas e foram coletados nos anos de 2011 (16 isolados) e 2010 (11 isolados), predominantemente, $(1764,1548,1779,1825$, $1743,1546,1547,1687,2530,1637,1859,1647,1900,2498,2219$, $1818,1706,2279,1787,1784,2117,2210,2500,2433,1795,1631$, $1770,1796,1894,2139,1652)$. Já os isolados 1669, 1670, 1678 e 2364 (Santo Amaro), 2227 (Ituberá), 2208 (Gandú), 2118 (Uruçuca), 2607 (Itabuna), 2469 (Belmonte), 2348 (Camacan), 2125 e 2171 (Uruçuca) e 2531 (Itacaré), apresentaram valores médios iguais ou inferiores a 1,5 e foram considerados os menos agressivos.

Coletados no ano de 2010, 42 isolados foram testados, sendo o mais agressivo o de registro número 1913, proveniente da Fazenda Humaíta, no município de Belmonte, seguido pelo de registro número 1733, obtido na Fazenda Dom João, no município de São Francisco do Conde, porém, nove outros isolados não diferiram estatisticamente do isolado 1913, sendo, portanto, considerados também de maior agressividade. Entre estes isolados, estão um de Belmonte (1767), três de Ilhéus (1546, 1547 e 1548), um de Una (2219), um de Mutuípe (2279), dois de Uruçuca (1706 e 2117) e um de Gandú (2210). Já os menos agressivos foram o isolado 2125, coletado na Fazenda Convenção, e 2171, da Fazenda Brasileira, ambas no município de Uruçuca, porém onze outros isolados não diferiram estatisticamente dos dois mencionados anteriormente.

No ano de 2011, o isolado mais agressivo entre os 41 isolados foi o de registro número 1744, proveniente da fazenda São Pedro, no município de Uruçuca, não só para o município, como também na comparação entre os 100 isolados testados seguido pelo isolado 1764 . Também foram considerados agressivos os isolados 1778 e 1735 ambos obtidos no município de Camacan, 1845 e 1779, de Mutuípe, 1985 e 1971, de Ilhéus, 1878, de Una e 1825, de Ituberá. Os isolados menos agressivos foram os de registros números 1670, 1678, 1669, obtidos de três propriedades agrícolas (Calmon-Mamão, Dom João e Engenho D’água), localizadas no município de Santo Amaro. No entanto, outros nove isolados também não diferiram do isolado 1670, foram eles 1940 e 1941, de Ilhéus, 1628 (Gandú), 1762 (Uruçuca), 1640 e 1927, de Itabuna, 1790 (Belmonte), 1836 (Ituberá) e 1862 (Una).

Já para o ano de 2012, quando apenas 17 isolados foram estudados, tanto os isolados mais agressivos, de registro número 2530 e 2498 , quanto o menos agressivo, de registro número 2531 , foram

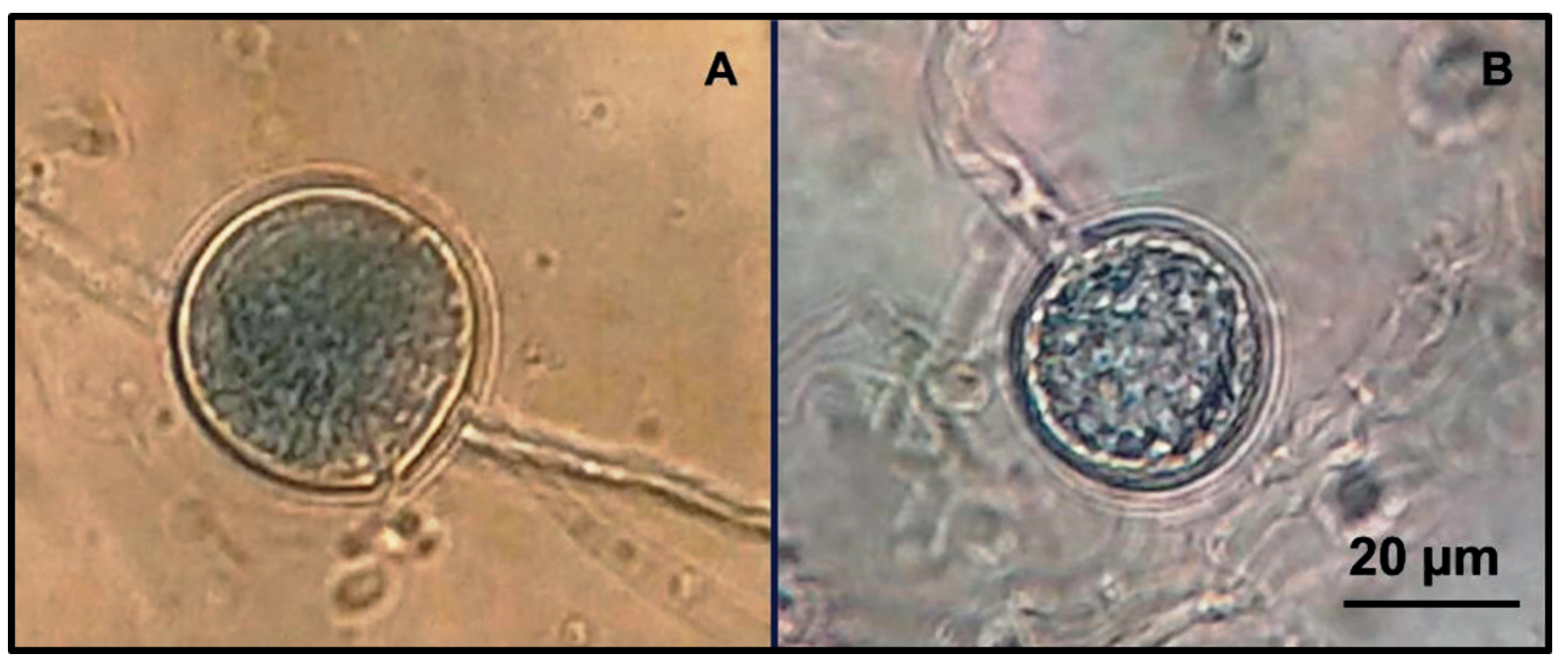

Figura 3. Clamidósporos dos isolados de P. palmivora estudados. (A) Intercalar; (B) Terminais. 


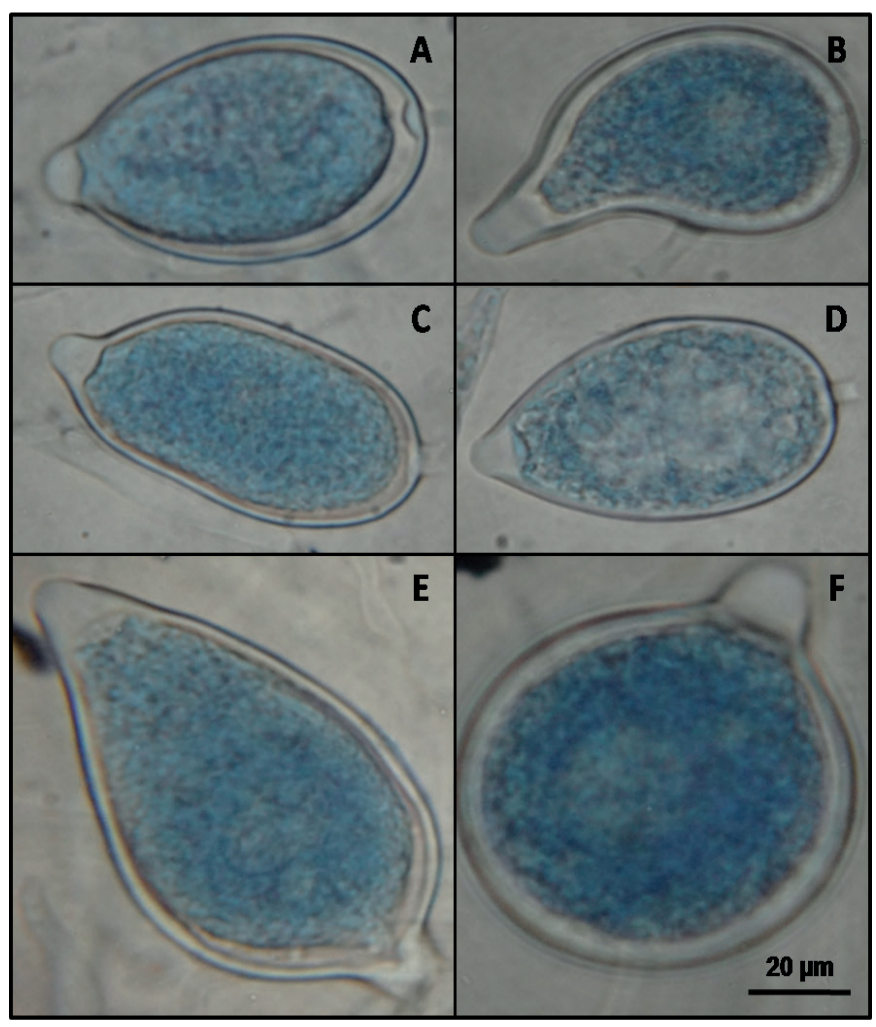

Figura 4.Formas dos esporângios de isolados de P. palmivora de cacaueiro; A: Ovóide; B: Distorcido; C: Elipsóide; D: Limoniforme; E: Obipiriforme e F: Globoso.

provenientes da Fazenda Três Irmãos, no município de Itacaré. Não diferiram estatisticamente dos isolados de Itacaré mais agressivos, os de registro número 2433 (Camacan), 2500 (Ilhéus), 2497 (Uruçuca) e 2466 (Belmonte); enquanto entre os menos agressivos estão também os de número 2469 (Belmonte), 2508 (Ilhéus), 2607 (Itabuna) e 2489 (Uruçuca).

Notou-se que houve variação entre as dimensões dos isolados considerados mais e menos agressivos. Por exemplo, na variação entre as médias das dimensões de esporângios, o isolado 1744, considerado o mais agressivo entre todos os isolados testados, apresentou a menor média de comprimento $(28,3 \mu \mathrm{m})$. Já o isolado 2207 , considerado menos agressivo entre os 100 isolados testados, apresentou o maior comprimento médio $(55,6 \mu \mathrm{m})$ entre os 61 isolados caracterizados morfometricamente.

Morfologicamente, os isolados de P. palmivora de cacaueiro apresentaram micélio hialino com hifas cenocíticas. Todos os isolados avaliados apresentaram produção abundante de esporângios caducos e papilados, com pedicelos curtos e, clamidósporos globosos, terminais ou intercalares, predominantemente terminais (Figura 3). Os isolados produziram esporângios predominantemente elipsoides e ovoides, embora outras formas estivessem presentes, como limoniformes, globosos e distorcidos (Figura 4). Essas características correspondem ao descrito para a espécie $P$. palmivora $(9,10)$. Resultados similares foram encontrados por outros autores em mamoeiro (4), jaca (2), abacateiro (25), citros (12) e damasco (39).

O comprimento (C) dos esporângios variou de 55,6 $\mu \mathrm{m}$ (2207) a $28,3 \mu \mathrm{m}$ (1744) e a largura (L) de 50,9 $\mu \mathrm{m}$ (1865) a $18 \mu \mathrm{m}$ (2117), com média de 41,5 - 27,8 $\mu$ m e a relação $\mathrm{C} / \mathrm{L}$ variou de 2,2 a 1,1 . As medidas da papila, profundidade (P) variaram de $8,3 \mu \mathrm{m}(1770)$ a 3,4 $\mu \mathrm{m}$ (2505) e largura (L) de 8,5 $\mu \mathrm{m}$ (2139) a 3,1 $\mu \mathrm{m}$ (2327) com média de 4,7 - 5,7 $\mu \mathrm{m}$. O pedicelo variou de um comprimento (C) de 1,5 $\mu \mathrm{m}$ (1669) a 6,6 $\mu \mathrm{m}$ (2327) com média de 3,2 $\mu \mathrm{m}$.

Os isolados de P. palmivora (BG-17 e BG-26) obtidos da pupunheira (Bactris gasipaes) para primeiro relato desta espécie causando a podridão do estipe da pupunheira no estado do Paraná, apresentaram dimensões similares às obtidas para esporângios neste estudo, (46,4 × 30,7 e 46,1 x 29,0), respectivamente (32). Em abacateiro (25) e em citros (12), também foram registradas médias das dimensões de esporângios similares em isolados de $P$. palmivora $(48,8 \times 31,8 \mu \mathrm{m}$ e 53,8 x 33,3 $\mu \mathrm{m})$, respectivamente. Isolados de $P$. palmivora obtidos a partir de plantas sintomáticas de damasco, apresentaram dimensões de estruturas que se aproximam das deste estudo, tanto para esporângios $(42,5 \times 36,0 \mu \mathrm{m})$ como para pedicelo $(3 \mu \mathrm{m})$ (39). Já em mamoeiro, no Estado de Alagoas, os esporângios mediram 37,6 x 27,5 m (4).

Os clamidósporos apresentaram diâmetro variando de $53,65 \mu \mathrm{m}$ (2139) a 18,4 $\mu \mathrm{m}$ (2402) com uma média de 31,7 $\mu \mathrm{m}$. A morfologia dos clamidósporos não varia muito entre as espécies de Phytophthora, sendo a importância desse caráter na taxonomia, na maioria das vezes, limitada à sua presença ou ausência (9). Clamidósporos com características similares aos verificados neste trabalho foram encontrados em outras pesquisas para $P$. palmivora em pupunheira, no Brasil (32), em citros, na Tailândia (12) e em damasco, na Turquia (39).

As colônias dos 100 isolados de P.palmivora apresentaram micélio

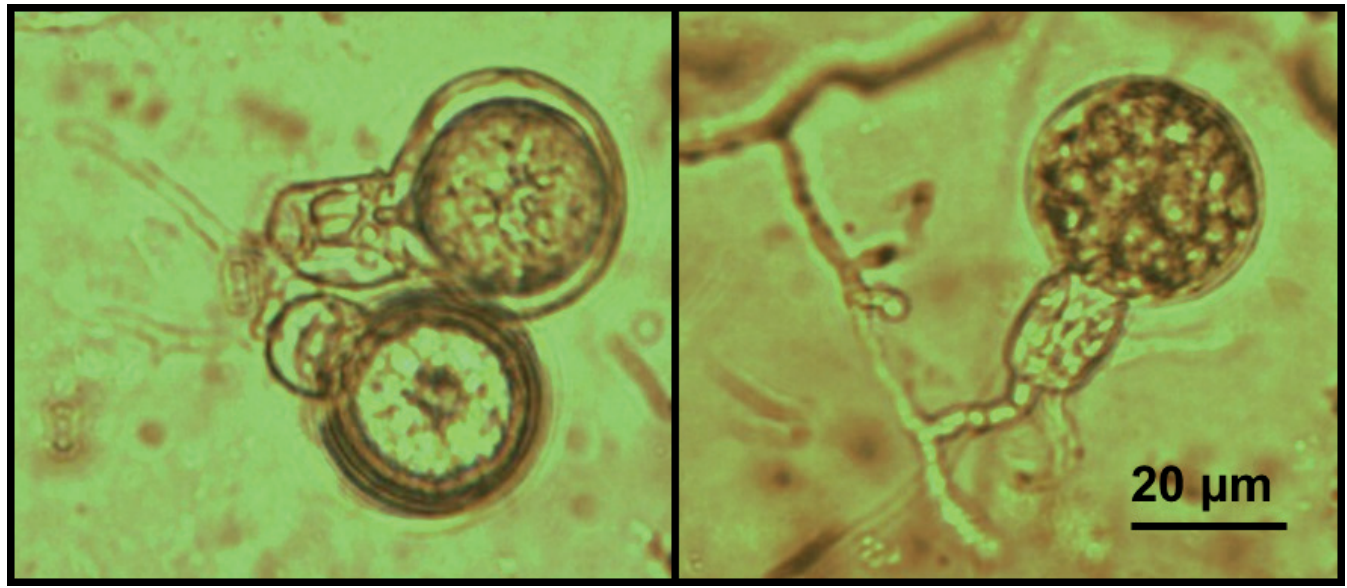

Figura 5. Oósporos com anterídios anfígenos dos isolados de P. palmivora estudados. 
superficial ralo e seis formas padrões de colônia: sem forma definida, estrelada, ligeiramente estrelada, rosácea, petaloide e ligeiramente petaloide, sendo o padrão mais frequente sem forma definida. Variações de padrões são comuns nas culturas de Phytophthora (9), tendo sido observadas em culturas de $P$. palmivora de pupunheira (32), de citros e damasco (12,39), onde os autores relatam estes mesmos padrões

Foi comprovada a natureza heterotálica de todos os isolados de P. palmivora de cacaueiro estudados, com presença apenas do tipo A2, pois formaram oogônio esférico, anterídios anfígenos e oósporos apleróticos (Figura 5), quando pareados com o isolado 1191, padrão de compatibilidade Al de $P$. palmivora de mamoeiro. Também foi observada a presença de anterídios anfígenos em culturas de $P$. palmivora de pupunheira (5).

Ficou comprovado por este estudo que existe variabilidade entre os 100 isolados de P. palmivora estudados, quanto a morfologia, o que de certo modo não excede muito os limites relatados na literatura para a espécie, conforme comentado anteriormente. Surpreendeu, no entanto, a alta variabilidade na agressividade dos isolados ao hospedeiro considerando a comparação das médias dos índices de doença obtidos em discos de folhas inoculadas com a mesma concentração de inóculo $\left(3,0 \times 10^{5}\right.$ zoósporos $\left./ \mathrm{mL}\right)$ para todos os isolados, que demonstrou haver isolados mais e menos agressivos nos diferentes locais e anos de coleta, não permitindo relacionar esta ocorrência ao local ou ao ano de coleta dos mesmos (Tabela 4). Poderiam ser levantadas três hipóteses para explicar esta alta variação na agressividade. A primeira teria sua causa na variabilidade climática que costuma ocorrer na região cacaueira da Bahia e que influí diretamente sobre as condições de temperatura e umidade do solo (34), principal reservatório de inóculo da Podridão Parda no campo; durante os meses mais quentes do ano (26), estas variações podem ter contribuído para nos anos de maior déficit de umidade, selecionar indivíduos mais vigorosos dentro da população do patógeno, independentemente de sua agressividade. A segunda, se relaciona com o material genético cultivado: nas últimas duas décadas, clones resistentes à Vassoura de Bruxa (VB) foram plantados em diversas propriedades rurais da região, no entanto, algumas conservaram os materiais genéticos tradicionais na região, para os quais deveria haver o equilíbrio com a população do patógeno vigente. O processo de adaptação aos novos genótipos pode ter causado impacto nessa população, gerando novos indivíduos mais agressivos, como tem ocorrido também para a VB $(11,28,30)$. Uma terceira hipótese explicativa se baseia na possibilidade de recombinação genética na população de $P$. palmivora ter ocorrido em alguns locais e anos em função de plantios consorciados com outros hospedeiros da espécie e que apresentem os dois tipos de compatibilidade sexual, o que possibilita a geração de novos indivíduos que podem ter maior ou menor agressividade aos hospedeiros de origem. Plantios consorciados ou em sistemas agroflorestais tornaram-se mais frequentes na região cacaueira após a introdução da VB (38). Phytophthora palmivora é uma espécie com ampla gama de hospedeiros no Brasil (19).

É possível inferir também que a variação obtida no decorrer dos anos para a ocorrência da Podridão Parda no campo seja devido à predominância de isolados mais agressivos na população (Figura 2 e Tabela 3).

A descoberta da ampla variação na agressividade dos isolados de $P$. palmivora do cacaueiro tem sérias implicações na avaliação de resistência de genótipos de cacaueiro a esta espécie, ou seja, ao invés de se utilizar somente um isolado padrão para os testes de resistência, após este resultado, fica claro que o melhor será utilizar uma mistura de isolados para a preparação da suspensão de inóculo para os testes de inoculação e avaliação da resistência em clones de cacaueiros. Só então avaliações de resistência poderão ser conduzidas com confiabilidade e acurácia.

\section{AGRADECIMENTOS}

A CAPES pela concessão da bolsa de Mestrado a primeira autora; ao Programa de Pós-Graduação em Produção Vegetal da UESC, Ilhéus-BA; à Comissão Executiva do Plano da Lavoura Cacaueira Ceplac/Cepec, onde toda a pesquisa foi realizada e aos funcionários dos laboratórios de Phytophthora e Ceratocystis do CEPEC pela colaboração; aos Professores Drs. Arlete Silveira, Jadergudson Pereira e Álvaro Figueiredo dos Santos pelas sugestões e contribuições a este trabalho; e ao Técnico em Agrimensura Jaime Araújo Santos pela compilação do Mapa.

\section{REFERÊNCIAS}

1. Bahia, R.C. de; Aguilar-Vildoso, C.I.; Luz, E.D.M.N.; Lopes, U.V.; Machado, R.C.R.; Corrêa, R.X. Resistance to Black Pod Disease in a Segregating Cacao Tree Population. Tropical Plant Pathology, Brasília, v. 40, p. 13-18, 2015.

2. Borines, L.M.; Palermo, V. G.; Guadalquiver, G. A.; Dwyer, C.; Drenth, A.; Daniel, R. \& Guest, D. I. "Jackfruit decline caused by Phytophthora palmivora (Butler).” Australasian Plant Pathology, Austrália, v. 43, p. 123-129, 2014

3. Bowers, J.H.; Bailey, B. A.; Hebbar, P.K.; Sanogo, S.; Lumsden, R.D. The impact of plant diseases on world chocolate production. Plant Health Progress, online, 2001. Disponível em: $<$ http://www.plantmanagementnetwork. org/pub/php/review/cacao>. Acesso em: 26 de abril, 2020.

4. Carnaúba, J.P.; Sobral, M. F.; Furtado, D.C.; Silva, I.O.; Silva, K. M.; Amorim, E. P. Phytophthora palmivora, agente da podridão de raiz e fruto de mamoeiro no estado de Alagoas. Revista Brasileira de Fruticultura, Jaboticabal, v. 28, p. 134-135, 2006.

5. Cerqueira, A.O.; Luz, E.D.M.N.; Rocha, C. S. S. Caracterização morfológica e biométrica de alguns isolados de Phytophthora spp. da micoteca do Centro de Pesquisas do Cacau. Fitopatologia Brasileira, Brasília, v. 24, n. 2, p. 114-119, 1999.

6. Dantas Neto, A.; Corrêa, R.X.; Monteiro, W. R.; Luz, E.D.M.N.; Gramacho, K. P.; Lopes, U.V. Caracterização de uma população de cacaueiro para mapeamento de genes de resistência à vassoura-de-bruxa e podridão-parda. Fitopatologia Brasileira, Brasília, v. 30, p. 380-386, 2005.

7. De Bary, A. Researches into the nature of the potato fungus Phytophthora infestans. Journal Research Agricultural Society English, London, v. 12, p. 239-269, 1876.

8. Dias, L.A.S. Melhoramento genético do cacaueiro. 1. ed. Viçosa, MG: FUNAPE, 578 p., 2001.

9. Erwin, D.C.; Ribeiro, O.K. (ed.). Phytophthora diseases worldwide. St. Paul: APS, 592 p., 1996.

10. Gallegly, M.E.; Hong, C.H (ed.). Phytophthora: identifying species by morphology and DNA fingerprints. St. Paul: APS, 168 p., 2008.

11. Gramacho, K.P.; Luz, E.D.M.N.; Silva, F.S.; Lopes, U.V.; Pires, J.L.; Santos Filho, L. P. dos. Pathogenic variability of Moniliophthora perniciosa in three agroecological zones of the cacao region of Bahia, Brazil. Crop Breeding and Applied Biotechnology, Viçosa JRC, v. 16, p. 7-13, 2016.

12. Hung, P.M.; Wattanachai, P.; Kasem, S.; Poaim, S. Biological control of Phytophthora palmivora causing root rot of pomelo using Chaetomium spp. Mycobiology, South Korea, v. 43, n. 1, p. 63-70, 2015.

13. Iwaro A.D.; Sreenivasan T.N.; Butler D. R.; Umaharan, P. Rapid screening for Phytophthora pod rot resistance by means of detached pod inoculation. In: Proceedings of the CFC/ICCO/IPGRI Project Workshop. IPIGRI, Montpellier, p. 109-113, 2000.

14. Kannwischer, M.E.; Mitchell, D.J. The influence of a fungicide on the epidemiology of black shank of tobacco. Phytopathology, St. Paul, v. 68, p. $1760-1765,1978$.

15. Luz, E.D.M.N.; Yamada, M.M. Índices para avaliar a reação de cultivares de cacau a Phytophthora spp. Revista Theobroma, Ilhéus, v. 14, n. 3, p. 
181-188, 1985.

16. Luz, E.D.M.N. The roles of five species of Phytophthora in infection and disease of roots, stems, and pods of Theobroma cacao $\mathrm{L}$. Thesis (Ph.D.) - University of Florida, Gainesville, 1989.

17. Luz, E.D.M.N.; Silva, S. D. V. M.; Yamada, M.M.; Pires, J.L.; Braga, M. C.T.; Lopes, U. V; Bezerra, J. L.; Brugnerotto, M.I.B. Research on cacao resistance to black pod disease in Bahia, Brazil - 1980 to 1995. In: International Workshop on the Contribution of Disease Resistance to Cocoa Variety Improvment - INGENIC, 1999, Salvador. Proceedings. Reading, UK: INGENIC, p. 57-65, 1996.

18. Luz, E.D.M.N.; Bezerra, J.L.; Resende, M.L.V.; Oliveira, M.L. Cacau controle de doenças. In: Vale, F. X. R, Zambolim, L. (ed.). Controle de doenças de plantas: grandes culturas. Viçosa: UFV, v. 2, p. 611-649, 1997.

19. Luz, E.D.M.N.; Santos, A.F. dos; Matsuoka, K.; Bezerra, J.L. Phytophthora: fungo, protista ou chromista? In: Luz, E.D.M.N.; Santos, Á.F. dos; Matsuoka, K.; Bezerra, J. L. (eds.) Doenças causadas por Phytophthora no Brasil. Campinas: Livraria e Editora Rural, v. 1, p. 1-22, 2001.

20. Luz, E.D.M.N.; Silva, S.D.V.M. Podridão-parda dos frutos, cancro e outras doenças causadas por Phytophthora no cacaueiro. In: Luz, E.D.M.N.; Santos, Á. F. dos; Matsuoka, K.; Bezerra, J. L. (eds.). Doenças causadas por Phytophthora no Brasil. 1. ed. Campinas: Livraria Editora Rural, v. 1, p. 175-265, 2001.

21. Luz, E. D. M. N. O gênero Phytophthora no Brasil. Fitopatologia Brasileira, Brasília, v. 3 p. 80-81. Suplemento, 2006.

22. Luz, E.D.M.N.; Silva, S.D.V.M.; Bezerra, J.L.; Souza, J.T. de; Santos A. F. dos. Glossário Ilustrado de Phytophthora: técnicas especiais para o estudo de oomicetos. Campinas: Livraria Editora Rural, p. 95-118, 2008.

23. Luz, E.D.M.N.; Magalhaes, D.M.A.; Santos, M.V.O. dos; Santos Filho, L.P. Atualidades no manejo de doenças do cacaueiro no Brasil. In: Núcleo de Estudos em Fitopatologia. (Org.). Patologia florestal: desafios e perspectivas. 1. ed. Lavras: Núcleo de Estudos em Fitopatologia, v.1, p. 313-334, 2013.

24. Luz, E.D.M.N.; Magalhaes, D.M.A.; Pimenta Neto, A.A.; Santos Filho, L.P.; Magalhães, L.A.; Farias Filho, A.F. Influência do sistema de cultivo na biogeografia das espécies de Phytophthora patogênicas ao cacaueiro na Bahia, Brasil. Agrotrópica, Ilhéus, BA, v. 30, n. 3, p. 205 - 214. 2018.

25. Machado, M.; Peña-Marey, M.; Alvarez, A.; Díaz, A.; Zamora, V.; Coto, O. Variabilidade intraespecífica de cepas de Phytophthora palmivora Butler (Butler) aisladas de plantaciones de aguacatero (Persea americana Mill.) en Cuba. Revista de Protección Vegetal, La Habana, v. 28, n. 3, p. 178-184, 2013.

26. Nyassé, S.; Cilas, C.; Hérail, C.; Blaha, G. Leaf inoculation as an early screening test for cocoa (Theobroma cacao L.) resistance to Phytophthora black pod disease. Crop Protection, United Kingdom, v. 14, p. 657-663, 1995.

27. Oliveira, M.L. de; Luz, E.D.M.N. Identificação e manejo das principais doenças do cacaueiro no Brasil. Ilhéus: CEPEC, 2005. p. 132.

28. Paim, V.R.L.; Luz, E.D.M.N.; Pires, J.L.; Silva, S.D.M.; Souza, J.T. de; Albuquerque, P.S.B.; Santos Filho, L.P. Sources of resistance to Crinipellis perniciosa in progenies of cacao accessions collected in the Brazilian Amazon. SCIENTIA AGRICOLA- JRC, São Paulo - SP, v. 63, n.6, p.
572-578, 2006

29. Pereira, J.L; Ram, A.; Figueiredo, J.M.; Almeida, L.C.C. Primeira ocorrência da vassoura-de-bruxa na principal região produtora do Brasil. Agrotrópica, Ilhéus, v.1, n.1, p.79-81, 1989.

30. Pires, J.L., Melo, G.R.P., Yamada, M.M, Gramacho, K.P Association among sources of resistance to witches' broom disease for the increment of the level and durability of the character In: 16th International Cocoa Research Conference, 2009, Bali, Indonésia. Proceedings of the 16th International Cocoa Research Conference. Lagos/Nigéria: COPAL/ CATIE, p.431 - 435, 2009

31. SAS (1990) User's guide: statistics version. Cary: SAS Institute. 846 p, 2005

32. Santos, A.F. dos; Luz, E.D.M.N.; Fianto, P.D.; Tessmann, D.J.; Vida, J.B Primeiro relato da podridão da base do estipe da pupunheira causado por Phytophthora palmivora, no Estado do Paraná. Fitopatologia Brasileira, Brasília, v. 30, p. 81-84, 2004.

33. Santos, E.S.L.; Cerqueira-Silva, C.B.M.; Clement, D.; Luz, E.D.M.N. Resistance gradient of black pod disease in cocoa and selection by leaf disc test. Crop Breeding and Applied Biotechnology, Viçosa, v. 11, p. 297-303, 2011.

34. Santos Filho, L.P. dos; Luz, E.D.M.N.; Marrocos, P.C.S.; Ruiz, M.M. Marques, J.R.B. Associação da precipitação pluvial na área tradiciona de plantio de cacao no Sul da Bahia com a frutificação e a incidência de doenças do cacaueiro. Ilhéus - BA CEPLAC/CEPEC. Boletim Técnico, n. 214. 30p. 2019.

35. Serra, M.; Lopes Marinho, P. Crescimento x desenvolvimento regional endógeno: uma análise da região cacaueira baiana, 1960-1980. RDE - Revista de Desenvolvimento Econômico, Salvador, v. 9, n. 15, p. 28-40, 2007.

36. Sereno, M.L.; Albuquerque, P.S.B.; Vencovsky, R.; Figueira, A. Genetic diversity and natural population structure of cacao (Theobroma cacao L.) from the Brazilian Amazon evaluated by microsatellite markers. Conservation Genetics, Dordrecht, v. 7, p. 13-24, 2006.

37. Stamps, D. J.; Waterhouse, G. M.; Newhook, F. J.; Hall, G. S. Revised tabular key to the species of Phytophthora. Mycological Papers, Wallingford, v. 162, n. 1, p. 1-28, 1990.

38. Tocafundo, F. Caracterização biológica, molecular e patogênica de $\boldsymbol{P h y}$ tophthora palmivora associada ao cacaueiro, mamoeiro e pupunheira. 111 f. Tese (Doutorado em Produção Vegetal) - Universidade Etadual de Santa Cruz, Ilhéus, 2019

39. Türkölmez, Ş.; Çiftçi, O.; Canihoş, E.; Serçe, Ç.U.; Derviş, S. Phytophthora Crown and Root Rot of Apricot Caused by Phytophthora palmivora in Turkey. Journal of Phytopathology, Berlin, v. 163, n. 6, p. 498-502, 2015.

40. Van Der Vossen, H.A.M. Strategies of variety improvement in cocoa with emphasis on durable disease resistance. An external review prepared for INGENIC. In: Proceedings of the international workshop on the contribution of disease resistance to cocoa variety improvement, Salvador, 24-26, November 1996. INGENIC, London, pp. 23-32, 1997.

41. Waterhouse, G.M. Key to the species of Phytophthora de Bary. Kew: Commonweath Mycological Institute Mycol, Pap 92, 1963. 